\title{
Trends in Fontan surgery and risk factors for early adverse outcomes after Fontan surgery: The Australia and New Zealand Fontan Registry experience
}

\author{
Ajay J. Iyengar, MBBS(Hons), BMedSci, ${ }^{\text {a,b }}$ David S. Winlaw, MBBS(Hons), MD, FRACS, ${ }^{c}$ \\ John C. Galati, BSc, PhD, ${ }^{b, j}$ David S. Celermajer, MBBS, PhD, DSc, MSc, FAHA, FRACP, FAA, ${ }^{d}$ \\ Gavin R. Wheaton, MBBS, FRACP, ${ }^{\mathrm{e}}$ Thomas L. Gentles, MBChB, FRACP, ${ }^{\mathrm{f}}$ Leeanne E. Grigg, MBBS, FRACP, ${ }^{\mathrm{g}}$ \\ Robert G. Weintraub, MBBS, FRACP, ${ }^{\mathrm{a}, \mathrm{b}}$ Andrew Bullock, MBBS, FRACP, \\ Robert N. Justo, MBBS, FRACP, ${ }^{\mathrm{i}}$ and Yves d'Udekem, MD, $\mathrm{PhD}^{\mathrm{a}, \mathrm{b}}$
}

Objectives: This study examined changes in practice and analyzed risk factors for adverse early outcomes after Fontan surgery through use of a binational, population-based registry.

\begin{abstract}
Methods: Demographic, preoperative, and perioperative data were collected from all participating institutions of the Australia and New Zealand Fontan Registry. Patient and operative characteristics were analyzed with multivariable logistic regression for impact on early mortality, early Fontan failure (death, takedown, or mechanical support), effusions (prolonging hospital stay $>30$ days or requiring surgical reintervention), and stay longer than 30 days.
\end{abstract}

\begin{abstract}
Results: Overall mortality was 3.5\% (37/1071) and declined throughout the study period, from 8\% (1975-1990) to $4 \%$ (1991-2000) and 1\% (2001-2010). There were no differences between the extracardiac and lateral tunnel modifications for any outcome. After 2006, the extracardiac conduit was performed exclusively, with $1.3 \%$ mortality. The proportion of patients with hypoplastic left heart syndrome rose to $17 \%$ in the current era, and this group had more effusions (odds ratio, 3.0; 95\% confidence interval, 1.4-6.6) and stayed on average 2 days longer in the hospital. Hypoplastic left heart syndrome was also an independent risk factor for composite adverse early outcome (death, failure, prolonged effusions, or prolonged stay $>30$ days; odds ratio, 2.6; 95\% confidence interval 1.4-4.8 respectively).
\end{abstract}

Conclusions: The extracardiac conduit is now the exclusive Fontan modification performed in Australia and New Zealand. Even with a higher proportion of high-risk cases, perioperative outcomes are excellent in the modern era. Hypoplastic left heart syndrome confers a higher risk of prolonged pleural effusion and early composite adverse outcome. (J Thorac Cardiovasc Surg 2014;148:566-75)

After Fontan and Baudet's initial description of the atriopulmonary connection, ${ }^{1}$ subsequent modifications were introduced in 1988 by de Leval and colleagues ${ }^{2}$ and in 1990 by Marcelletti and associates. ${ }^{3}$ The atriopulmonary connection has now been abandoned because of the survival attrition of these patients and the progressive decline in functional capacity. ${ }^{4-6}$ It has long been assumed that the lateral tunnel and the extracardiac conduit techniques would yield equivalent early outcomes, and that differences between these techniques would only become obvious in the

From the Cardiac Surgery and Cardiology Departments, ${ }^{\text {a }}$ Royal Children's Hospital, Melbourne, Australia; the Murdoch Childrens Research Institute, ${ }^{\mathrm{b}}$ Melbourne, Australia; the Heart Centre for Children, ${ }^{\mathrm{c}}$ The Children's Hospital at Westmead, Sydney, Australia; the Department of Cardiology, ${ }^{\mathrm{d}}$ Royal Prince Alfred Hospital, Sydney, Australia; the Department of Cardiology, ${ }^{\mathrm{e}}$ Women's and Children's Hospital, Adelaide, Australia; the Green Lane Congenital Cardiac Service, ${ }^{\mathrm{f}}$ Starship Children's Hospital, Auckland, New Zealand; the Department of Cardiology, ${ }^{\mathrm{g}}$ The Royal Melbourne Hospital, Melbourne, Australia; the Children's Cardiac Centre, ${ }^{\text {h }}$ Princess Margaret Hospital for Children, Perth, Australia; Paediatric Cardiology, ${ }^{\mathrm{i}}$ Queensland Paediatric Cardiac Service, Mater Children's Hospital, Brisbane, Queensland, Australia; and the Department of Mathematics and Statistics, ${ }^{\mathrm{j}}$ La Trobe University, Melbourne, Australia.

Supported by the Victorian Government's Operational Infrastructure Support Program. The Australia and New Zealand Fontan Registry is funded by grants from the NHMRC (APP1012241) Heart Kids and the ANZ Bank Trustees. analysis of long-term outcomes after Fontan surgery. In a recent report from the Society of Thoracic Surgeons Congenital Heart Surgery Database, patients undergoing an extracardiac conduit were found to have a higher risk of early reintervention and failure and were likely to stay in the hospital longer than those undergoing the lateral tunnel. ${ }^{7}$ Along with the modification of techniques, the population offered Fontan surgery has evolved during the course of the last 2 decades. In particular, the improved survival after Norwood surgery has been responsible for an increase in the

Y.d'U. is a Career Development Fellow of The National Heart Foundation of Australia (CR 10M 5339). A.J.I. has received postgraduate awards from the Royal Australasian College of Surgeons (Catherine Marie Enright Kelly and Eric Bishop Scholarships) and the National Health and Medical Research Council (NHMRC) and The National Heart Foundation of Australia (APP1038802).

Disclosures: Andrew Bullock reports consulting fees from Actelion. All other authors

have nothing to disclose with regard to commercial support.

Received for publication March 18, 2013; revisions received Aug 12, 2013; accepted

for publication Sept 30, 2013; available ahead of print Nov 25, 2013.

Address for reprints: Ajay J. Iyengar, MBBS(Hons), BMedSci, Department of Cardiac Surgery, Royal Children's Hospital, Flemington Rd, Parkville, VIC 3052, Australia (E-mail: ajayjiyengar@gmail.com).

$0022-5223 / \$ 36.00$

Copyright (C) 2014 by The American Association for Thoracic Surgery

http://dx.doi.org/10.1016/j.jtcvs.2013.09.074 

Abbreviations and Acronyms
CI = confidence interval
HLHS = hypoplastic left heart syndrome
$\mathrm{IQR}=$ interquartile range
OR = odds ratio

proportion of patients with hypoplastic left heart syndrome (HLHS) reaching Fontan surgery. 8

In 2008, the Australia and New Zealand Fontan Registry was established to clarify long-term expectations of patients undergoing Fontan procedures and to enable recruitment of larger numbers of patients into prospective studies. During the creation and recruitment of patients into this registry, the preoperative and perioperative data of all patients undergoing Fontan procedures in Australia and New Zealand were collected. We thus sought to determine trends in indications and demographic characteristics of patients undergoing the Fontan procedure since its introduction in the region in 1975 and to analyze the impact of these trends on early outcomes, with a focus on the surgical techniques used. This analysis represents the entire experience of Fontan surgery in Australia and New Zealand.

\section{MATERIALS AND METHODS}

Institutional approval to collect data at all participating centers was obtained, and the need for consent was waived because of the retrospective nature of the study. All Fontan procedures performed in Australia and New Zealand were identified by consulting the cardiac surgical and cardiology databases at each institution (Appendix Table 1). Preoperative, perioperative, and early postoperative data collected are described in Appendix Table 2. Operative reports, echocardiographic reports, and discharge summaries were reviewed. Patients for whom insufficient data existed to satisfy the minimum data set (age at Fontan, Fontan type, and discharge status) were excluded. Fontan conversions were excluded from the data set, with the exception of 3 patients who had previously undergone a Björk procedure and subsequently had a Fontan completion.

\section{Outcomes}

The primary outcome was early mortality, defined as death within the first 30 postoperative days or before hospital discharge if the stay was longer than 30 days. Secondary outcomes were early failure (takedown, major reintervention not bleeding related, including Fontan revision, fenestration creation, enlargement or closure, mechanical circulatory support, or percutaneous reintervention), prolonged effusions (lasting $>30$ days or requiring reoperation for transcatheter intervention, pleurodesis, or Fontan revision), and a composite adverse early outcome (death, failure, prolonged effusions, or prolonged stay $>30$ days).

\section{Statistical Analysis}

Patient, operative and outcome data were described according to era and Fontan type (Tables 1 and 2), with normally distributed, nonnormally distributed, and proportional data described as mean $\pm \mathrm{SD}$, median with interquartile range (IQR), and number and percentage, respectively. Logistic regression analysis models were constructed for each outcome, and multivariable models were designed a priori to compare lateral tunnel versus extracardiac Fontan types and morphologically left versus right ventricles while adjusting for sex, age, and morphology as categoric variables. Remaining covariates were analyzed in univariable models to identify potential confounders and entered into the multivariable models if they were associated with a large effect size (odds ratio $(\mathrm{OR}) \geq 2.5$ or $\leq 0.4$ ) or there was evidence against the null hypothesis of no association (2-tailed $P \leq .05$ ). Because of collinearity between Fontan type, era, staging with bidirectional cavopulmonary shunt, and fenestration, we included only Fontan type in multivariable models. Additionally, southern hemisphere respiratory syncytial virus season (the months of May to September) was analyzed for its effect on pleural effusions. The variables selected for multivariable models and their regression parameters are reported in Table 3.

Exposure groups in which no failures or deaths occurred could not be entered into logistic regression models. Numeric covariates were analyzed as continuous variables unless a nonlinear relationship could be demonstrated between covariate and outcome. Linearity was examined by performing a likelihood ratio test comparing regression models with continuous covariates against models in which the numeric variable had been categorically transformed. Age at Fontan operation had nonlinear associations with mortality (Figure 1) and the other end points and was analyzed as a categoric variable.

All analyses were performed with the Stata 11.2 statistical software package (StataCorp, College Station, Tex).

\section{RESULTS \\ Description of Cohort}

In all, 1095 Fontan procedures were identified, of which 1071 had sufficient data to be included for analysis.

A total of 1989 previous surgical palliations were performed in 990 patients. Previous staging with bidirectional cavopulmonary shunt occurred in 636 patients $(59 \%)$ : 4\% who underwent the atriopulmonary technique, $16 \%$ who underwent lateral tunnel, and $96 \%$ who underwent extracardiac conduit. Mean pre-Fontan pulmonary arterial pressure was lowest among patients with extracardiac conduits (11.1 \pm $2.7 \mathrm{~mm} \mathrm{Hg}$ for extracardiac, $12.5 \pm 4.5 \mathrm{~mm} \mathrm{Hg}$ for lateral tunnel, and $13.1 \pm 4.3 \mathrm{~mm} \mathrm{Hg}$ for atriopulmonary; $P<.001$; $\left.R^{2}=0.05\right)$. The proportion with detected aortopulmonary collaterals increased with each era (3 patients [3\%] before 1991, 47 patients [16\%] from 1991 to 2000 , and 115 patients [30\%] after 2000), and 46 of 165 patients (28\%) had these embolized before the Fontan procedure by transcatheter coiling. At 1 center, internal thoracic to pulmonary artery collaterals were routinely divided at operation if visualized.

Moderate or severe atrioventricular valve regurgitation was present before the Fontan procedure in a total of 65 patients $(7.5 \%)$. Of the whole cohort, 40 patients $(4.6 \%)$ had previously undergone atrioventricular valve repair or replacement; $18(45 \%)$ were left with recurrent regurgitation by the time of the Fontan procedure, but rerepair was only attempted in 9 patients. Atrioventricular valve repair was undertaken concomitantly with the Fontan procedure in 28 patients $(3 \%, 9$ re-repairs and 19 de novo repairs).

Extracardiac conduit was the only modification performed after July 2006. Fenestration was performed in $50 \%$ of lateral tunnel and $44 \%$ of extracardiac connections. 
TABLE 1. Description of baseline data by Fontan type

\begin{tabular}{|c|c|c|c|c|}
\hline Variable & AP (1975-1995) & LT (1988-2006) & ECC (1997-2010) & Total \\
\hline No. of patients & $239(22 \%)$ & $296(28 \%)$ & $536(50 \%)$ & 1071 \\
\hline Age (y, median and IQR) & $5.6(3.2-9.3)$ & $3.8(2.8-5.8)$ & $4.8(3.9-6.0)$ & $4.7(3.4-6.5)$ \\
\hline Male (No.) & $132(55 \%)$ & $166(56 \%)$ & $320(60 \%)$ & $618(58 \%)$ \\
\hline \multicolumn{5}{|l|}{ Ventricular morphology } \\
\hline Left & $185(77 \%)$ & $183(62 \%)$ & $289(54 \%)$ & $657(61 \%)$ \\
\hline Right & $44(18 \%)$ & $93(32 \%)$ & $190(36 \%)$ & $327(31 \%)$ \\
\hline Biventricular/indeterminate & $10(4 \%)$ & $19(6 \%)$ & $57(11 \%)$ & $86(8 \%)$ \\
\hline \multicolumn{5}{|l|}{ Morphologic group } \\
\hline TA & $79(33 \%)$ & $73(25 \%)$ & $101(19 \%)$ & $253(24 \%)$ \\
\hline HLHS & $2(1 \%)$ & $9(3 \%)$ & $78(15 \%)$ & $89(8 \%)$ \\
\hline DORV & $34(14 \%)$ & $45(15 \%)$ & $71(13 \%)$ & $150(14 \%)$ \\
\hline CAVC & $13(5 \%)$ & $17(6 \%)$ & $34(6 \%)$ & $64(6 \%)$ \\
\hline TGA & $6(3 \%)$ & $18(6 \%)$ & $27(5 \%)$ & $51(5 \%)$ \\
\hline ccTGA & $10(4 \%)$ & $13(4 \%)$ & $28(5 \%)$ & $51(5 \%)$ \\
\hline DILV & $52(22 \%)$ & $65(22 \%)$ & $78(15 \%)$ & $195(18 \%)$ \\
\hline PA-IVS & $17(7 \%)$ & $20(7 \%)$ & $47(9 \%)$ & $84(8 \%)$ \\
\hline CAVC-DORV & $6(3 \%)$ & $16(5 \%)$ & $26(5 \%)$ & $48(4 \%)$ \\
\hline Other & $20(8 \%)$ & $20(7 \%)$ & $46(9 \%)$ & $86(8 \%)$ \\
\hline \multicolumn{5}{|l|}{ Anatomic comorbidities } \\
\hline Isomerism or heterotaxy & $11(5 \%)$ & $22(7 \%)$ & $39(7 \%)$ & $72(7 \%)$ \\
\hline Dextrocardia or mesocardia & $22(9 \%)$ & $18(6 \%)$ & $39(7 \%)$ & $79(7 \%)$ \\
\hline \multicolumn{5}{|l|}{ Previous operations } \\
\hline No. $($ mean $\pm \mathrm{SD})$ & $1.2 \pm 0.8$ & $1.6 \pm 0.9$ & $2.3 \pm 1.0$ & $1.9 \pm 1.0$ \\
\hline PA banding (No. and \%) & $55(23 \%)$ & $86(29 \%)$ & $141(26 \%)$ & $282(26 \%)$ \\
\hline Norwood procedure (No. and \%) & $2(1 \%)$ & $10(3 \%)$ & $81(15 \%)$ & $93(9 \%)$ \\
\hline Aortic arch intervention (No. and \%) & $17(7 \%)$ & $48(16 \%)$ & $185(35 \%)$ & $250(23 \%)$ \\
\hline BCPS (No. and \%) & $9(4 \%)$ & $111(38 \%)$ & $516(96 \%)$ & $636(59 \%)$ \\
\hline PA reconstruction (No. and \%) & $5(2 \%)$ & $18(6 \%)$ & $113(21 \%)$ & $136(13 \%)$ \\
\hline \multicolumn{5}{|l|}{ Pre-Fontan hemodynamics } \\
\hline Arterial oxygen saturation (per $\%$, median and IQR; $\mathrm{n}=839$ ) & $81(77-85)$ & $82(78-85)$ & $82(78-86)$ & $82(78-86)$ \\
\hline $\mathrm{PA}$ pressure $(\mathrm{mm} \mathrm{Hg}$, mean $\pm \mathrm{SD} ; \mathrm{n}=869)$ & $13.1 \pm 4.3$ & $12.5 \pm 4.5$ & $11.1 \pm 2.7$ & $11.9 \pm 3.7$ \\
\hline$\geq$ Moderate AV valve regurgitation (No.; $\mathrm{n}=871$ ) & $9(8 \%)$ & $12(5 \%)$ & $44(9 \%)$ & $65(7 \%)$ \\
\hline Arteriovenous malformations (No.; $\mathrm{n}=809$ ) & $2(2 \%)$ & $6(3 \%)$ & $32(7 \%)$ & $40(5 \%)$ \\
\hline Collaterals (No.; $\mathrm{n}=799$ ) & $2(2 \%)$ & $21(10 \%)$ & $142(29 \%)$ & $165(21 \%)$ \\
\hline \multicolumn{5}{|l|}{ Operative variables (No.) } \\
\hline Concomitant procedure & $31(13 \%)$ & $52(18 \%)$ & $73(14 \%)$ & $156(15 \%)$ \\
\hline Fenestration & $0(0 \%)$ & $149(50 \%)$ & $236(44 \%)$ & $385(36 \%)$ \\
\hline RSV seasonality (May to September) & $108(45 \%)$ & $130(44 \%)$ & $183(34 \%)$ & $421(39 \%)$ \\
\hline
\end{tabular}

When data were not available for all patients, values are given for study set and study set size is specified. $A P$, Atriopulmonary; $L T$, lateral tunnel; $E C C$, extracardiac conduit; $I Q R$, interquartile range; $T A$, tricuspid atresia; $H L H S$, hypoplastic left heart syndrome; DORV, double-outlet right ventricle; CAVC, complete atrioventricular canal; $T G A$, transposition of the great arteries; $c c T G A$, congenitally corrected transposition of the great arteries; DILV, double-inlet left ventricle; PA-IVS, pulmonary atresia with intact ventricular septum; $P A$, pulmonary artery; $B C P S$, bidirectional cavopulmonary shunt; $A V$, atrioventricular; $R S V$, respiratory syncytial virus.

Pulmonary artery rehabilitation (percutaneous or surgical) was undertaken in a total of 191 patients $(18 \%)$ at some stage during life: 55 patients underwent pulmonary artery patch reconstruction at the time of the Fontan procedure, 126 had surgical reconstruction or stenting before Fontan completion, and an additional 10 had both previous and concomitant intervention to the pulmonary arteries.

Age at Fontan completion varied according to Fontan type. The extracardiac conduit was performed 1 year later than the lateral tunnel (median, 4.8 years; IQR, 3.9-6.0 years; vs median, 3.8 years; IQR, 2.8-5.8 years; $P<.001)$.
The proportion of patients with HLHS rose during the regional experience, from $1 \%$ in the era to 1990 , to $3 \%$ between 1991 and 2000 and $17 \%$ after 2000. The peak proportion of patients undergoing Fontan surgery with HLHS was $28 \%$ in 2007 . HLHS was present in $15 \%$ of patients undergoing extracardiac Fontan procedures.

\section{Early Mortality}

The early outcomes of patients are represented graphically in Figure 2 and in tabular form in Tables 2 and 4. Results of logistic regression analysis for each outcome are presented in Table 3. 
TABLE 2. Description of early outcomes according to era

\begin{tabular}{|c|c|c|c|c|}
\hline Outcome & 1975-1990 & 1991-2000 & 2001-2010 & Total \\
\hline No. & $246(23 \%)$ & $371(35 \%)$ & $454(42 \%)$ & 1071 \\
\hline Early mortality & $19(8 \%)$ & $13(4 \%)$ & $5(1 \%)$ & $37(3.5 \%)$ \\
\hline Early failure* & $21(9 \%)$ & $27(7 \%)$ & $17(4 \%)$ & $65(6 \%)$ \\
\hline Prolonged effusions $\dagger$ & $11(4 \%)$ & $28(8 \%)$ & $35(8 \%)$ & $74(7 \%)$ \\
\hline Composite adverse early outcome $\neq$ & $48(26 \%)$ & $61(20 \%)$ & $56(12 \%)$ & $165(17 \%)$ \\
\hline Prolonged stay $(>30 \mathrm{~d})$ & $29(16 \%)$ & $37(12 \%)$ & $44(10 \%)$ & $110(12 \%)$ \\
\hline Stay among survivors $(\mathrm{d}$, median and $\mathrm{IQR} ; \mathrm{n}=913)$ & $15.5(12-27)$ & $12(9-20)$ & $13(9-20)$ & $13(10-21)$ \\
\hline
\end{tabular}

Data are expressed as No. and \% except as specified. IQR, Interquartile range. *Death, mechanical support, takedown, or major reoperation. $\dagger$ Pleural effusions persisting $>30$ days or requiring surgical intervention. †ุProlonged effusions, failure, or prolonged stay ( $>30$ days).

TABLE 3. Univariate and multivariate logistic regression results for each end point

\begin{tabular}{|c|c|c|c|c|c|c|c|c|c|c|c|c|c|c|c|}
\hline \multirow[b]{3}{*}{ Variable } & \multicolumn{4}{|c|}{ Early mortality $(n=37)$} & \multicolumn{4}{|c|}{ Early failure $(n=65)$} & \multicolumn{4}{|c|}{ Prolonged effusions $(n=75)$} & \multicolumn{3}{|c|}{$\begin{array}{l}\text { Composite adverse early } \\
\text { outcome }(n=165)\end{array}$} \\
\hline & \multirow{2}{*}{$\begin{array}{c}\text { Univariate } \\
P \\
\text { value }\end{array}$} & \multicolumn{3}{|c|}{ Multivariate } & \multirow{2}{*}{$\begin{array}{c}\text { Univariate } \\
P \\
\text { value } \\
\end{array}$} & \multicolumn{3}{|c|}{ Multivariate } & \multirow{2}{*}{$\begin{array}{c}\text { Univariate } \\
P \\
\text { value }\end{array}$} & \multicolumn{3}{|c|}{ Multivariate } & \multirow{2}{*}{$\begin{array}{c}\text { Univariate } \\
P \\
\text { value }\end{array}$} & \multicolumn{2}{|c|}{ Multivariate } \\
\hline & & OR & $\begin{array}{c}\mathbf{9 5} \% \\
\mathbf{C I}\end{array}$ & $\begin{array}{c}P \\
\text { value }\end{array}$ & & OR & $\begin{array}{c}\mathbf{9 5} \% \\
\text { CI }\end{array}$ & $\begin{array}{c}P \\
\text { value }\end{array}$ & & OR & $\begin{array}{c}\mathbf{9 5} \% \\
\mathbf{C I}\end{array}$ & $\begin{array}{c}P \\
\text { value }\end{array}$ & & $\begin{array}{cc} & 95 \% \\
\text { OR } & \text { CI } \\
\end{array}$ & $\begin{array}{c}P \\
\text { value }\end{array}$ \\
\hline \multicolumn{16}{|l|}{ Fontan type } \\
\hline Lateral tunnel & Ref & Ref & Ref & Ref & Ref & Ref & Ref & Ref & Ref & Ref & Ref & Ref & Ref & Ref Ref & Ref \\
\hline Atriopulmonary & $<.001$ & 3.9 & $1.1-13.2$ & .03 & .05 & 1.7 & $0.6-4.9$ & .4 & .5 & 0.9 & $0.4-1.9$ & .7 & .006 & $1.60 .7-3.6$ & .3 \\
\hline $\begin{array}{l}\text { Extracardiac } \\
\text { conduit }\end{array}$ & .4 & 1.2 & $0.3-4.6$ & .8 & .2 & 0.6 & $0.2-1.3$ & .2 & .2 & 1.1 & $0.6-2.0$ & .7 & .2 & $0.90 .5-1.6$ & .7 \\
\hline \multicolumn{16}{|l|}{ Age (y) } \\
\hline $4-5$ & Ref & Ref & Ref & Ref & Ref & Ref & Ref & Ref & Ref & Ref & Ref & Ref & Ref & Ref Ref & Ref \\
\hline$<4$ & .05 & 4.5 & $0.6-37$ & .2 & .3 & 1.2 & $0.5-3.2$ & .9 & .04 & 0.6 & $0.3-1.1$ & .08 & .3 & $0.70 .4-1.3$ & .2 \\
\hline $5-8$ & .09 & 3.6 & $0.4-32$ & .2 & .6 & 0.9 & $0.3-2.8$ & .9 & .04 & 0.5 & $0.3-1.0$ & .05 & .3 & $0.50 .3-1.1$ & .07 \\
\hline$>8$ & .01 & 6.5 & $0.8-55$ & .09 & .2 & 1.5 & $0.5-4.7$ & .5 & .05 & 0.5 & $0.2-1.2$ & .1 & 6 & $0.70 .3-1.5$ & .4 \\
\hline Male sex & 6 & 1.2 & $0.7-4.5$ & .2 & .2 & 1.8 & $0.9-3.9$ & .1 & .9 & 0.8 & $0.5-1.3$ & .4 & .5 & $0.80 .5-1.3$ & .3 \\
\hline \multicolumn{16}{|c|}{ Ventricular morphology } \\
\hline Left & Ref & & & & Ref & Ref & Ref & Ref & Ref & Ref & Ref & Ref & Ref & Ref Ref & Ref \\
\hline Right & .8 & & & & .9 & 0.8 & $0.3-1.7$ & .5 & .01 & 1.2 & $0.7-2.2$ & .5 & .4 & & \\
\hline $\begin{array}{l}\mathrm{BiV} \text { or } \\
\text { indeterminate }\end{array}$ & .3 & & & & .09 & 2.2 & $0.8-6.5$ & .1 & 6 & 1.3 & $0.5-3.2$ & .6 & .5 & & \\
\hline \multicolumn{16}{|l|}{ Morphologic group } \\
\hline $\mathrm{TA}$ & Ref & & & & Ref & & & & Ref & $*$ & & & Ref & Ref Ref & Ref \\
\hline HLHS & .4 & & & & .6 & & & & $<.001$ & 3.1 & $1.4-6.6$ & .005 & .02 & $2.7 \quad 1.2-6.0$ & .01 \\
\hline DORV & .9 & & & & .9 & & & & $>.99$ & & & & .4 & $1.00 .4-2.3$ & $>.99$ \\
\hline CAVC & .9 & & & & .4 & & & & 6 & & & & .06 & $2.10 .8-5.3$ & .1 \\
\hline TGA & $-\dagger$ & & & & .2 & & & & .7 & & & & .8 & $1.20 .3-4.6$ & .8 \\
\hline ccTGA & .4 & & & & .4 & & & & .4 & & & & .2 & $1.50 .5-4.3$ & .4 \\
\hline DILV & .3 & & & & .3 & & & & .4 & & & & .4 & $1.10 .5-2.3$ & .9 \\
\hline PA-IVS & .8 & & & & .9 & & & & .7 & & & & $>.99$ & $1.0 \quad 0.4-2.8$ & $>.99$ \\
\hline CAVC-DORV & .3 & & & & .3 & & & & .3 & & & & .3 & $2.00 .6-6.6$ & .2 \\
\hline Other & .4 & & & & .2 & & & & .2 & & & & .7 & $0.90 .3-2.4$ & .8 \\
\hline \multicolumn{16}{|c|}{ Anatomic comorbidities } \\
\hline $\begin{array}{r}\text { Isomerism or } \\
\text { heterotaxy }\end{array}$ & .3 & & & & .07 & & & & .3 & & & & .07 & & \\
\hline $\begin{array}{l}\text { Dextrocardia } \\
\text { or mesocardia }\end{array}$ & .2 & & & & .04 & 2.3 & $0.8-6.4$ & .1 & .5 & & & & .04 & $1.40 .6-3.3$ & .4 \\
\hline \multicolumn{16}{|l|}{ Previous operations } \\
\hline No. & .003 & 1.0 & $0.6-1.6$ & .9 & .06 & & & & .1 & & & & .01 & $0.90 .7-1.2$ & .7 \\
\hline PA banding & .2 & & & & .8 & & & & .9 & & & & .7 & & \\
\hline $\begin{array}{l}\text { Aortic arch } \\
\text { intervention }\end{array}$ & .2 & & & & .8 & & & & .001 & - & & & .3 & & \\
\hline
\end{tabular}




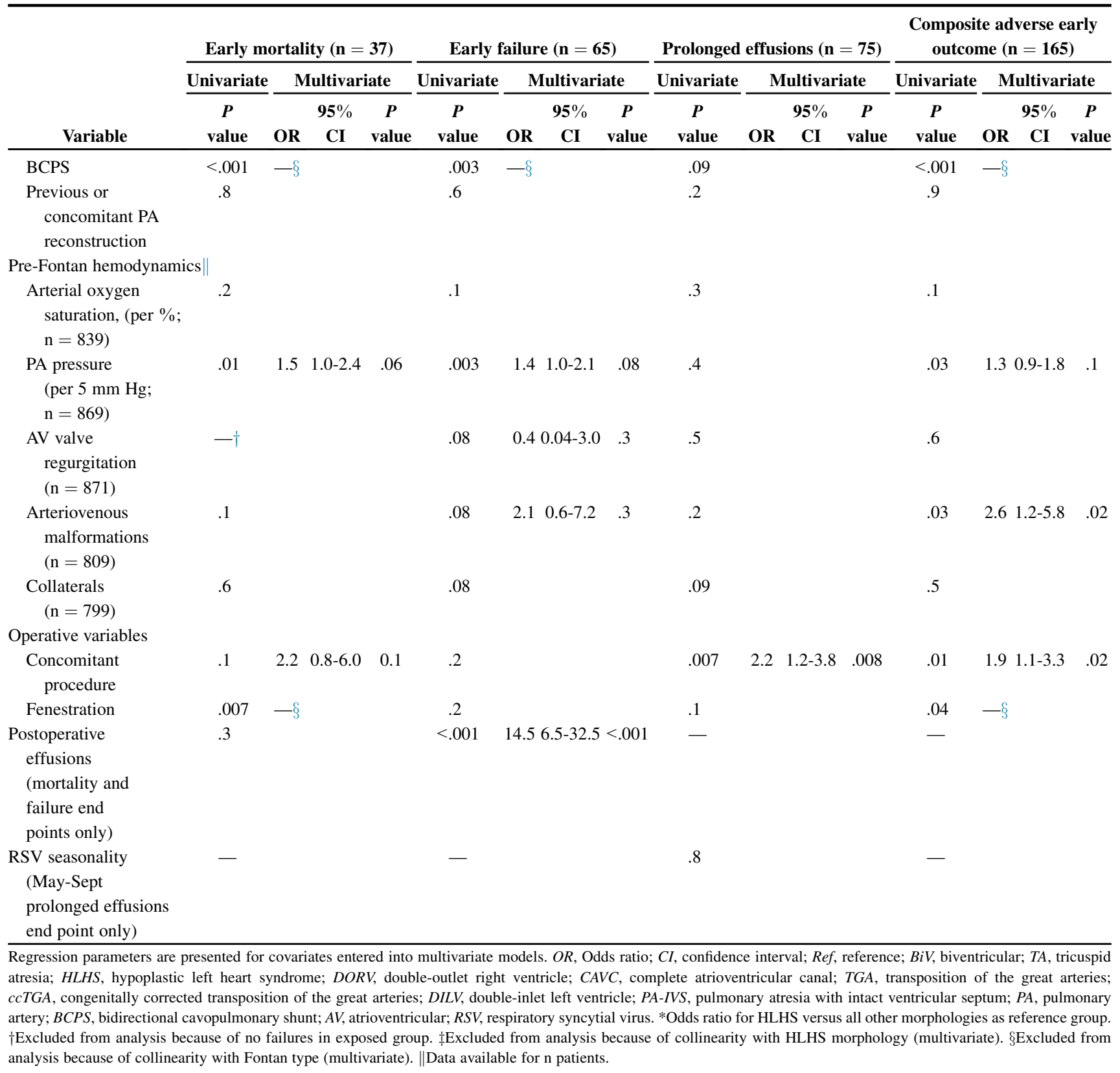

There were a total of 37 early deaths: 2 intraoperative, 3 after reintervention, 5 after takedown, and 26 not associated with any major reintervention. Early mortalities after extracardiac conduit and lateral tunnel modifications were low (7/536 [1.3\%] and 6/296 [2.0\%], respectively; $P=.4)$, with higher early mortality after atriopulmonary connection $(24 / 239[10 \%])$. A $1 \%$ mortality was achieved in the current era (Table 2). Risk factors associated with early mortality after adjustment for age and sex were atriopulmonary connection technique (OR, 3.9; 95\% CI, 1.113.2) and preoperative elevation of pulmonary arterial pressure (OR, 1.5 per 5-mm Hg increase; 95\% CI, 1.02.4). Mortalities after lateral tunnel and extracardiac conduit did not differ (OR, 1.2; 95\% CI, 0.3-4.6) independent of era. Fontan completion at 4 to 5 years of age was weakly associated with markedly lower univariate odds of mortality when compared with those younger than 4 years (OR, 4.5; 95\% CI, 0.6-37), 5 to 8 years old (OR, 3.6; $95 \% \mathrm{CI}, 0.4-32)$, and older than 8 years (OR, 6.5; 95\% CI, 0.8-55). Despite large effect sizes in univariate models, however, the age of completion no longer reached statistical significance in the multivariate model. 


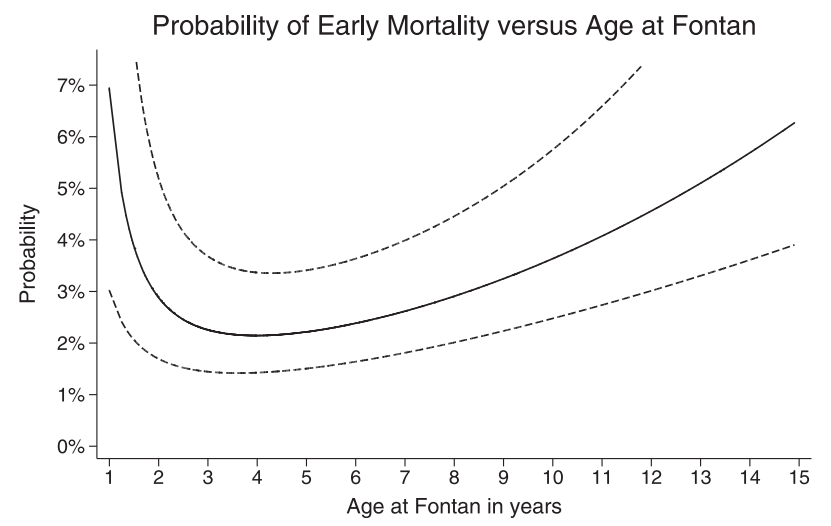

FIGURE 1. Probability of early mortality against age at Fontan, obtained by means of fractional polynomial regression. Dashed lines indicate upper and lower $95 \%$ confidence limits.

\section{Early Failure (Death, Takedown, Major}

Reintervention, or Mechanical Circulatory Support)

Early failure occurred in $6 \%$ of patients $(65 / 1071)$. Among the 20 patients undergoing early Fontan takedown, $15(75 \%)$ survived to hospital discharge with an intermediate palliation (10 bidirectional cavopulmonary shunts, 2 central shunts, 2 hemi-Fontan procedures, and 1 Kawashima procedure; Figure 2). In total, 5 patients required mechanical circulatory support (extracorporeal membrane oxygenation, $\mathrm{n}=4$; ventricular assist device, $\mathrm{n}=1$ ), 3 of whom survived to hospital discharge. Two of these patients were put on extracorporeal membrane oxygenation after early reintervention (1 each revision and takedown). Prolonged pleural effusion was the only independent predictor of increased risk of early failure (OR, 14.5; 95\% CI, 6.5-32.5). There were no deaths or failures among the 40 patients who had undergone concomitant or previous atrioventricular valve repair or replacement.

\section{Pleural Effusions, Prolonged Stay, and Composite Adverse Early Outcome}

Prolonged effusions occurred in 74 patients $(7 \%)$, and the mortality among these patients was 5\% (4/74, univariate $P=.8)$. In 37 of these patients, 61 reoperations were undertaken; these included 7 takedowns, 9 revisions, 1 conversion, 9 embolizations or division of collaterals, 20 pleurodeses, 3 percutaneous fenestration dilatations, and 1 thoracic duct ligation. In multivariable models, HLHS and concomitant procedure at the time of the Fontan operation were strongly associated with prolonged effusions (OR, 3.1; 95\% CI, 1.46.6; and OR, 2.2; 95\% CI, 1.2-3.8, respectively). There was no association between prolonged effusions and Fontan completion during the southern hemisphere respiratory syncytial virus season (May to September).

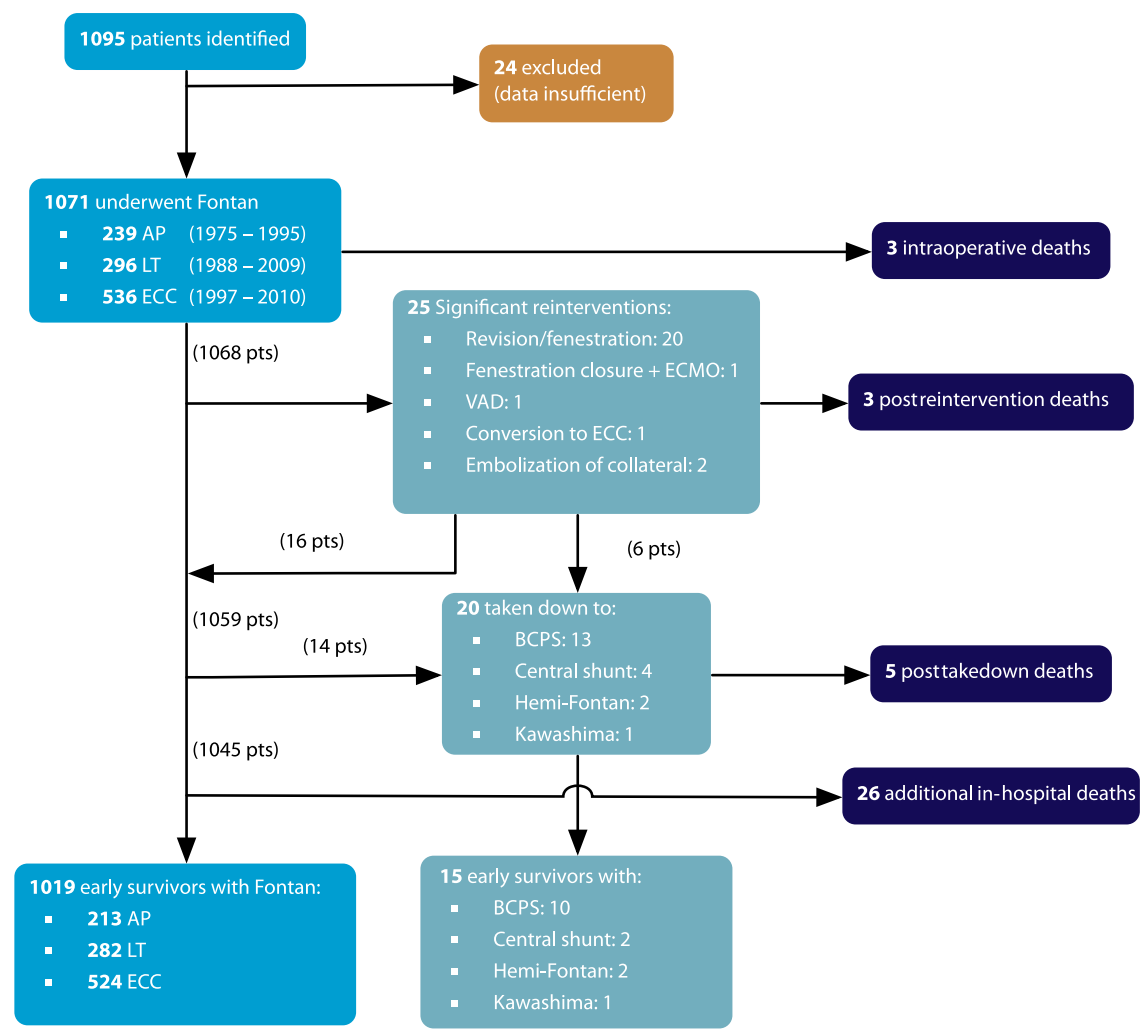

FIGURE 2. Surgical progression and early outcomes. $A P$, Atriopulmonary; $L T$, lateral tunnel; $E C C$, extracardiac; pts, patients; $E C M O$, extracorporeal membrane oxygenation; $V A D$, ventricular assist device; $B C P S$, bidirectional cavopulmonary shunt. 
TABLE 4. Description of early outcomes according to Fontan type

\begin{tabular}{|c|c|c|c|c|}
\hline Outcome & $\mathbf{A P}$ & $\mathbf{L T}$ & ECC & Total \\
\hline No. & $239(22 \%)$ & $296(28 \%)$ & $536(50 \%)$ & 1071 \\
\hline Early mortality & $24(10 \%)$ & $6(2.0 \%)$ & $7(1.3 \%)$ & $37(3.5 \%)$ \\
\hline Early failure* & $26(11 \%)$ & $18(6 \%)$ & $21(4 \%)$ & $65(6 \%)$ \\
\hline Prolonged effusions $\dagger$ & $11(5 \%)$ & $18(6 \%)$ & $45(8 \%)$ & $74(7 \%)$ \\
\hline $\begin{array}{l}\text { Composite adverse early } \\
\text { outcome } \ddagger\end{array}$ & $55(29 \%)$ & $39(17 \%)$ & $71(13 \%)$ & $165(17 \%)$ \\
\hline Prolonged stay ( $>30 \mathrm{~d})$ & $31(16 \%)$ & $26(12 \%)$ & $53(10 \%)$ & $110(12 \%)$ \\
\hline $\begin{array}{l}\text { Stay among survivors }(\mathrm{d}, \\
\text { median and IQR; } \mathrm{n}=913)\end{array}$ & $16(12-27)$ & $12(10-20)$ & $13(9-20)$ & $13(10-21)$ \\
\hline
\end{tabular}

Data are expressed as No. and \% except as specified. AP, Atriopulmonary; $L T$, lateral tunnel; ECC, extracardiac conduit; $I Q R$, interquartile range. *Death, mechanical support, takedown, or major reoperation. $\dagger$ Pleural effusions persisting $>30$ days or requiring surgical intervention. $\ddagger$ Prolonged effusions, failure, or prolonged stay ( $>30$ days).

Median hospital stay was 13 days (IQR, 10-21 days); patients with HLHS and atrioventricular septal defects, respectively, stayed 2 and 5 days longer than other groups $(P=.04$ and $P=.008)$, and this was the principal driver for the identification of HLHS as the strongest independent predictor (OR, 2.7; 95\% CI, 1.2-6.0) of the composite adverse early outcome end point (death, failure, prolonged effusions, or stay $>30$ days). The remaining independent risk factors are presented in Table 4.

Permanent pacemaker was required by discharge in 23 patients $(2 \%$; atriopulmonary, $\mathrm{n}=8$; lateral tunnel, $\mathrm{n}=4$; extracardiac conduit, $\mathrm{n}=11$ ).

\section{DISCUSSION}

Our study is based on a unique, binational populationbased registry that captures all available patients undergoing a Fontan procedure. We believe this design provides the most accurate data by eliminating potential referral and selection bias, as well as exploring outcomes for patients undergoing similar procedures in different institutions.

\section{Trends in Fontan Surgery}

It is likely that our experience in Australia and New Zealand reflects changes in Fontan surgery evident elsewhere. The preoperative condition of patients has improved, as reflected by the decrease in the proportion of patients with elevated preoperative pulmonary arterial pressures. It is remarkable that today the Fontan procedure has become an operation with $1 \%$ to $2 \%$ early mortality and a rate of early failure of $4 \%$. We have replaced the atriopulmonary technique, which was associated with worse outcomes, ${ }^{5}$ with the lateral tunnel and now extracardiac modifications.

The most striking change seen in our practice in the last decade has been the increasing proportion of patients with HLHS who are offered Fontan surgery, which is the direct result of the improved survival of these patients after their initial surgeries. This subset of patients represents the worst end of the spectrum of patients offered Fontan surgery, ${ }^{9,10}$ and it is therefore remarkable that the mortality associated with Fontan surgery has decreased during the same period, remaining around 1\% in Australia and New Zealand. It is likely that a better understanding of the Fontan physiology, and resultant better patient selection, has improved the preoperative and postoperative management of patients. In particular, the improved care of atrioventricular valve regurgitation, ${ }^{11,12}$ collaterals, ${ }^{13}$ and pulmonary arteriovenous malformations have probably contributed to these improved outcomes. This increasing population with HLHS have low mortality similar to that of the other patients but create increased demands on the health system. Disproportionate use of inpatient cardiac critical care services by single-ventricle patients, in particular those with HLHS, has already been observed. ${ }^{14,15}$ Our study highlights that they have more early adverse outcomes and stay longer in the hospital because of their tendency to have prolonged effusions. This association had already been demonstrated by Gaynor and colleagues ${ }^{16}$ and Rogers and associates ${ }^{17}$ and cannot be clearly linked only to adverse morphology. Patients with HLHS have undergone more extensive surgery during earlier operations. It is possible that previous damage to the network of chylous channels around the aorta during the initial surgery and repetitive extensive dissections predispose these patients toward chyle leaks. The recent report of Stewart and coworkers ${ }^{7}$ demonstrated that patients undergoing an extracardiac conduit were at risk for prolonged hospital stay, and we have hypothesized that this may be related to more extensive dissection with this technique. ${ }^{18}$ The prolonged effusions observed in patients with HLHS could also be related to adverse physiologic characteristics not apparent in Stewart and coworkers' earlier study, ${ }^{7}$ such as a trend toward more atrioventricular valve regurgitation, more aortopulmonary collaterals, or higher end-diastolic ventricular pressure. One wonders whether patients like these who have a higher rate of early complications will perhaps be prone to earlier failure of the Fontan circulation. 


\section{Fontan Type and Age at Fontan Completion}

There has been little clinical evidence that either of the prevailing techniques, the lateral tunnel and the extracardiac cardiac conduit, is superior to the other. Nevertheless, theoretic advantages have led all teams in Australia and New Zealand independently to adopt the extracardiac conduit technique.

Importantly, in our experience, there were no differences in the odds of development of any adverse early outcome between the lateral tunnel and extracardiac conduit modifications. This is in contrast to the recently published findings of Stewart and coworkers, ${ }^{7}$ who demonstrated increased odds of Fontan takedown, revision, Fontan failure, and longer postoperative stay after the extracardiac modification than after the lateral tunnel. The key difference between our series is the age at elective Fontan completion. Stewart and coworkers ${ }^{7}$ explicitly excluded patients older than 6 years from the analysis; however, these patients represent $30 \%$ of our cohort (318/1071). The reported North American experience reflects a willingness to proceed with Fontan completion at a very early age, with half of the patients operated on younger than 3 years. In Australia and New Zealand, by contrast, Fontan completion is undertaken at a later age, at a median of 4.7 years in the current era, and fewer than $7 \%$ of contemporary patients in this series had their Fontan procedure completed before the age of 3 years. The use of the lateral tunnel may be advantageous at such an early age, because the use of the extracardiac conduit will result in a size discrepancy between the adult-sized conduit and small vascular structures. Conduit size and the ratio of inferior vena cava to conduit diameter may be an important determinant of early outcomes, as the use of a conduit that is too large in a small patient promotes stagnation of caval flow and may contribute to loss of the respiratory pump, essential for inspiratory augmentation of pulmonary blood flow, and promote thrombosis formation in the early postoperative period. ${ }^{19,20}$ We have previously suggested that construction of the extracardiac conduit may be more prone to subtle technical deficiencies, such as distortion of the pulmonary arteries and a suboptimal fenestration, which are difficult to analyze without imaging data. ${ }^{18}$ These factors may also play a role in early hemodynamics and thus in outcomes.

We were interested to find that in our practice the age of 4 to 5 years was associated with better outcome according to univariate analysis but not in the multivariate model. It can be easily understood that within a policy of completing the Fontan around 4 years, patients younger than 4 years would be a select group with worse symptoms, such as those with pulmonary arteriovenous malformations and severe cyanosis. It is notable that later age at surgery seems to be associated with worse late functional outcomes but also worse early outcomes. ${ }^{21}$

\section{Atrioventricular Valve Regurgitation}

Atrioventricular valve regurgitation in patients with a single ventricle is likely to become an increasing issue in our patient population, and it appears to evolve to significantly adversely affect the course of patients during staged palliation despite an absence of truly discouraging longterm survival data. ${ }^{5,22,23}$ One in 10 patients in this series either displayed moderate to severe regurgitation immediately preoperatively, had previously undergone valve repair or replacement, or underwent repair or replacement at the time of the Fontan procedure. This series validates that excellent outcomes for these patients can be expected in the short term, ${ }^{24}$ despite a trend toward more effusions in those who undergo concomitant surgery.

\section{Limitations}

This study is limited by its retrospective nature. Direct comparisons between different surgical modifications are clearly confounded by the fact that these were undertaken during different eras during the binational experience. Because of the very close correlation between era and atriopulmonary Fontan type, correction for era was not possible. It is thus not possible to conclude whether the poorer outcomes after the atriopulmonary Fontan procedure were driven primarily by the early era during which these procedures were undertaken or by the procedure itself. In reality, we suspect a combination of these factors.

Similarly, staging could not be analyzed in multivariable models because it was so strongly associated with the development of the later Fontan modifications. We have previously demonstrated that the introduction of staging before Fontan completion entailed a selection process. ${ }^{25}$ Finally, this registry does not encompass all patients with single-ventricle physiology. This means that the true selection bias is not quantifiable, and the size of the era effect on patient selection is not known.

\section{CONCLUSIONS}

In conclusion, in Australia and New Zealand, all centers have progressively adopted the extracardiac conduit technique and offer Fontan surgery to patients around 4 to 5 years old. In this setting, the extracardiac conduit can be performed with a mortality of $1 \%$ and achieve similar early outcomes to the lateral tunnel. Patients with HLHS have more early complications, in particular pleural effusions, and this makes them a greater burden on delivery of care.

\section{References}

1. Fontan F, Baudet E. Surgical repair of tricuspid atresia. Thorax. 1971;26:240-8. 2. de Leval MR, Kilner P, Gewillig M, Bull C. Total cavopulmonary connection: a logical alternative to atriopulmonary connection for complex Fontan operations. 
Experimental studies and early clinical experience. J Thorac Cardiovasc Surg. 1988;96:682-95.

3. Marcelletti C, Corno A, Giannico S, Marino B. Inferior vena cava-pulmonary artery extracardiac conduit. A new form of right heart bypass. J Thorac Cardiovasc Surg. 1990;100:228-32.

4. Fontan F, Kirklin JW, Fernandez G, Costa F, Naftel DC, Tritto F, et al. Outcome after a "perfect" Fontan operation. Circulation. 1990;81:1520-36.

5. d'Udekem Y, Iyengar AJ, Cochrane AD, Grigg LE, Ramsay JM, Wheaton GR, et al. The Fontan procedure: contemporary techniques have improved long-term outcomes. Circulation. 2007;116(11 Suppl):I157-64.

6. d'Udekem Y, Cheung MM, Setyapranata S, Iyengar AJ, Kelly P, Buckland N, et al. How good is a good Fontan? Quality of life and exercise capacity of Fontans without arrhythmias. Ann Thorac Surg. 2009;88:1961-9.

7. Stewart RD, Pasquali SK, Jacobs JP, Benjamin DK, Jaggers J, Cheng J, et al. Contemporary Fontan operation: association between early outcome and type of cavopulmonary connection. Ann Thorac Surg. 2012;93:1254-60; discussion 1261

8. d'Udekem Y, Xu MY, Galati JC, Lu S, Iyengar AJ, Konstantinov IE, et al. Predictors of survival after single-ventricle palliation: the impact of right ventricular dominance. J Am Coll Cardiol. 2012;59:1178-85.

9. Tweddell JS, Hoffman GM, Mussatto KA, Fedderly RT, Berger S, Jaquiss RD, et al. Improved survival of patients undergoing palliation of hypoplastic left heart syndrome: lessons learned from 115 consecutive patients. Circulation. 2002; 106(12 Suppl 1):I82-9.

10. Czosek RJ, Anderson JB, Heaton PC, Cassedy A, Schnell B, Cnota JF. Staged palliation of hypoplastic left heart syndrome: trends in mortality, cost, and length of stay using a national database from 2000 through 2009. Am J Cardiol. 2013; 111:1792-9.

11. Ohye RG, Gomez CA, Goldberg CS, Graves HL, Devaney EJ, Bove EL. Tricuspid valve repair in hypoplastic left heart syndrome. J Thorac Cardiovasc Surg. 2004;127:465-72.

12. Nakata T, Fujimoto Y, Hirose K, Tosaka Y, Ide Y, Tachi M, et al. Atrioventricular valve repair in patients with functional single ventricle. J Thorac Cardiovasc Surg. 2010;140:514-21.

13. Reinhardt Z, De Giovanni J, Stickley J, Bhole VK, Anderson B, Murtuza B, et al. Catheter interventions in the staged management of hypoplastic left heart syndrome. Cardiol Young. Epub 2013 Feb 8.
14. Dean PN, Hillman DG, McHugh KE, Gutgesell HP. Inpatient costs and charges for surgical treatment of hypoplastic left heart syndrome. Pediatrics. 2011;128: e1181-6.

15. Menon SC, McCandless RT, Mack GK, Lambert LM, McFadden M, Williams RV, et al. Clinical outcomes and resource use for infants with hypoplastic left heart syndrome during bidirectional Glenn: summary from the Joint Council for Congenital Heart Disease National Pediatric Cardiology Quality Improvement Collaborative Registry. Pediatr Cardiol. 2013;34:143-8.

16. Gaynor JW, Bridges ND, Cohen MI, Mahle WT, Decampli WM, Steven JM, et al. Predictors of outcome after the Fontan operation: is hypoplastic left heart syndrome still a risk factor? J Thorac Cardiovasc Surg. 2002;123:237-45.

17. Rogers LS, Glatz AC, Ravishankar C, Spray TL, Nicolson SC, Rychik J, et al. 18 years of the Fontan operation at a single institution: results from 771 consecutive patients. J Am Coll Cardiol. 2012;60:1018-25.

18. Iyengar AJ, Konstantinov IE, Brizard CP, d'Udekem Y. Unreliable associations between type of Fontan and early outcome? Ann Thorac Surg. 2013;95:774-5.

19. Alexi-Meskishvili V, Ovroutski S, Ewert P, Dähnert I, Berger F, Lange PE, et al Optimal conduit size for extracardiac Fontan operation. Eur J Cardiothorac Surg. 2000; $18: 690-5$.

20. Itatani K, Miyaji K, Tomoyasu T, Nakahata Y, Ohara K, Takamoto S, et al. Optimal conduit size of the extracardiac Fontan operation based on energy loss and flow stagnation. Ann Thorac Surg. 2009;88:565-72; discussion 572-3.

21. Shiraishi S, Yagihara T, Kagisaki K, Hagino I, Ohuchi H, Kobayashi J, et al. Impact of age at Fontan completion on postoperative hemodynamics and long-term aerobic exercise capacity in patients with dominant left ventricle. Ann Thorac Surg. 2009;87:555-60; discussion 560-1.

22. Driscoll DJ, Offord KP, Feldt RH, Schaff HV, Puga FJ, Danielson GK. Five- to fifteen-year follow-up after Fontan operation. Circulation. 1992;85:469-96.

23. Gentles TL, Mayer JE Jr, Gauvreau K, Newburger JW, Lock JE, Kupferschmid JP, et al. Fontan operation in five hundred consecutive patients: factors influencing early and late outcome. J Thorac Cardiovasc Surg. 1997;114:376-91.

24. Kerendi F, Kramer ZB, Mahle WT, Kogon BE, Kanter KR, Kirshbom PM. Perioperative risks and outcomes of atrioventricular valve surgery in conjunction with Fontan procedure. Ann Thorac Surg. 2009;87:1484-8; discussion 1488-9.

25. Tan AM, Iyengar AJ, Donath S, Bullock AM, Wheaton G, Grigg L, et al. Fontan completion rate and outcomes after bidirectional cavo-pulmonary shunt. Eur J Cardiothorac Surg. 2010;38:59-65.

APPENDIX TABLE 1. Participating Institutions

\begin{tabular}{|c|c|c|c|c|c|}
\hline Victoria & New South Wales & Queensland & South Australia & Western Australia & New Zealand \\
\hline $\begin{array}{l}\text { The Royal } \\
\text { Melbourne Hospital }\end{array}$ & $\begin{array}{l}\text { The Children's Hospital, } \\
\text { Westmead }\end{array}$ & $\begin{array}{l}\text { Prince Charles } \\
\text { Hospital }\end{array}$ & $\begin{array}{l}\text { The Women's and } \\
\text { Children's Hospital }\end{array}$ & $\begin{array}{l}\text { Princess } \\
\text { Margaret Hospital }\end{array}$ & $\begin{array}{l}\text { Starship } \\
\text { Children's Hospital }\end{array}$ \\
\hline $\begin{array}{l}\text { The Royal } \\
\text { Children's Hospital }\end{array}$ & $\begin{array}{l}\text { Sydney Children's } \\
\text { Hospital }\end{array}$ & $\begin{array}{l}\text { Mater Children's } \\
\text { Hospital }\end{array}$ & $\begin{array}{l}\text { Royal Adelaide } \\
\text { Hospital }\end{array}$ & $\begin{array}{l}\text { Royal } \\
\text { Perth Hospital }\end{array}$ & \\
\hline $\begin{array}{l}\text { Monash Medical } \\
\text { Centre }\end{array}$ & $\begin{array}{l}\text { The Royal Prince } \\
\text { Alfred Hospital }\end{array}$ & & & & \\
\hline
\end{tabular}




\section{APPENDIX TABLE 2. Variables collected}

Patient characteristics

Demographic characteristics

Sex

Age (grouped $<4,4$ to 5,5 to $8, \geq 8$ )

Year of Fontan (grouped: 1975-1990, 1991-2000, 2001-2010 )

Diagnosis

Tricuspid atresia

Hypoplastic left heart syndrome

Double outlet right ventricle

Complete atrioventricular canal

Transposition of the great arteries

Congenitally corrected transposition

Double inlet left ventricle

Pulmonary atresia with intact ventricular septum

Complete atrioventricular canal with double outlet right ventricle

Other

Morphology

Dextrocardia or mesocardia

Presence of common atrioventricular valve

Ventricular morphology (grouped: left, right, indeterminate, biventricular)

Previous surgery

Pulmonary artery band

Aortic arch procedure (including Damus, Norwood, or arch reconstruction)

Pulmonary artery reconstruction before or at time of Fontan

Atrioventricular valve repair before or at time of Fontan

Bidirectional cavopulmonary shunt (grouped: unilateral, bilateral,

Kawashima, hemi-Fontan)

Preoperative hemodynamics

Mean pulmonary arterial pressure

Arterial oxygen saturation

Atrioventricular valve regurgitation (graded moderate or greater)

Operative characteristics

Type of Fontan

Atriopulmonary

Lateral tunnel

Extracardiac conduit

Procedure related

Presence of fenestration

Concomitant procedures

Postoperative course

Mortality during initial hospital stay or within $30 \mathrm{~d}$

Length of stay (prolonged if $>30 \mathrm{~d}$ )

Mechanical circulatory support (ECMO or VAD)

Major reoperation (including takedown, revision, or permanent pacemaker)

Effusions requiring reoperation or prolonging hospital stay $>30 \mathrm{~d}$

ECMO, Extracorporeal membrane oxygenation; $V A D$, ventricular assist device. 